\title{
Efficacy of morphological indexing of ovarian tumor: preoperative determination of risk of malignancy
}

\author{
Jagan Aishwarya*, Ramasamy Sasikala, Syed Dilshath
}

Department of Obstetrics and Gynecology, Government Rajaji Hospital, Madurai Medical College, Madurai, India

Received: 23 May 2017

Accepted: 20 June 2017

\section{*Correspondence:}

Dr. Jagan Aishwarya,

E-mail: aishupandi85@gmail.com

Copyright: (C) the author(s), publisher and licensee Medip Academy. This is an open-access article distributed under the terms of the Creative Commons Attribution Non-Commercial License, which permits unrestricted non-commercial use, distribution, and reproduction in any medium, provided the original work is properly cited.

\begin{abstract}
Background: Ovarian cancers ranks fifth in cancer death worldwide and in India it ranks third among the female genital tract malignancies. Objective of present study was to assess prospectively the efficacy of morphological indexing (MI) as a method to predict malignancy in sonographically confirmed ovarian tumors.

Methods: A prospective study conducted in a tertiary care hospital in Tamil Nadu from September 2011 to August 2012. The risk of malignancy is preoperatively assessed in 136 patients with ovarian tumour using a morphological index based on tumour volume and wall structure. Each tumour was assigned a score of 0 to 10 based on increasing volume and morphologic complexity. The efficacy of the index was assessed by histopathological examination of the tumour.

Results: The benign tumours had a mean MI score of 4.3 and malignant tumours had a mean of 8.3 which was statistically significant. Of the 54 tumours with MI $<5$, only $2(3.7 \%)$ were malignant where else out of the remaining 82 tumours with $\mathrm{MI}>5,54(51.2 \%)$ were malignant. With $\mathrm{MI}>5$ as a predictor of malignancy the present study had a Sensitivity-95.5\%, Specificity-56.5\%, Positive predictive value-51.2\%, Negative predictive value-94\%, and Accuracy-68\%.

Conclusions: Morphological index is a simple, valuable and inexpensive diagnostic tool to rule out malignancy in pre operative evaluations of ovarian tumors.
\end{abstract}

Keywords: Morphological indexing, Malignancy, Ovarian tumour

\section{INTRODUCTION}

Ovarian cancers ranks fifth in cancer death worldwide and in India it ranks third among the female genital tract malignancies. ${ }^{1}$ In India, the annual percentage of increase in age standardised incidence rates ranged from $0.7 \%$ to $2.4 \% .^{2,3}$ Of all gynaecological cancers, ovarian malignancies represent the greatest clinical challenge, because of greater range and variety of tumors with uncertain origin, no known premalignant lesion and variability in the rate of disease progression. Around $70 \%$ of patients with ovarian tumors are diagnosed only at advanced stages due to unavailability of effective screening method and lack of specific clinical presentations at early stage of the disease where the prognosis is poor. In contrast, women with early stage ovarian cancer have an excellent survival rates. ${ }^{4}$ Hence, there has been an increased interest in the development of investigations that can detect ovarian cancer at an early stage. Moreover, pre-operative knowledge about the nature of the ovarian tumour is necessary to plan surgery. A malignant tumour requires radical surgery, chemotherapy and counselling regarding the survival rates in contrast to the benign tumors that can be managed with simple laparoscopic cystectomy or laparotomy. This signifies the need for a preoperative 
determination of the nature of an ovarian tumor before deciding on the appropriate plan of management. ${ }^{5}$

The primary objective was to assess the efficacy of morphological index as a method to predict malignancy in sonographically confirmed ovarian tumors.

\section{METHODS}

This prospective observational study was conducted in Department of Obstetrics and Gynecology, in Govt. Rajaji Hospital, Madurai from September 2011 to August 2012. The study was approved by the institute ethical committee. Informed consent was taken from the patients prior to inclusion of individuals into the study. A standard proforma was used for collection of data.

The study was conducted on 136 patients with ovarian mass admitted for laparotomy.

\section{Inclusion criteria}

- Women with clinical diagnosis and sonographically confirmed ovarian mass of any age group.

\section{Exclusion criteria}

- Associated with other conditions like fibroid, PID, pregnancy, endometriosis and other concurrent malignancy.

- Women not fit for surgery or inoperable cases.

\section{Morphological index}

Transvaginal sonography was performed on all patients using a $5 \mathrm{MHz}$ transducer. The ovarian mass was measured in all its three dimensions and the volume of the ovary was calculated with the use of the prolate ellipsoid formula (length $\mathrm{x}$ width $\mathrm{x}$ height $\mathrm{x}$ 0.523). Cystic ovarian tumor with a papillary projections and solid areas, echogenicity, presence of septum and the presence or absence of free fluid in the extratumoral space were noted (Figure 1-7). Morphology indexing was performed according to DePriest and colleagues. ${ }^{6}$

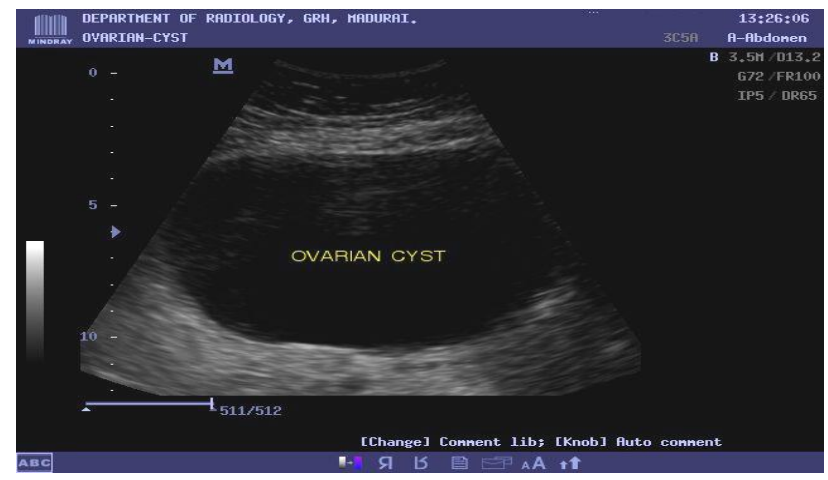

Figure 1: Smooth wall, Sonolucent (Score 0).

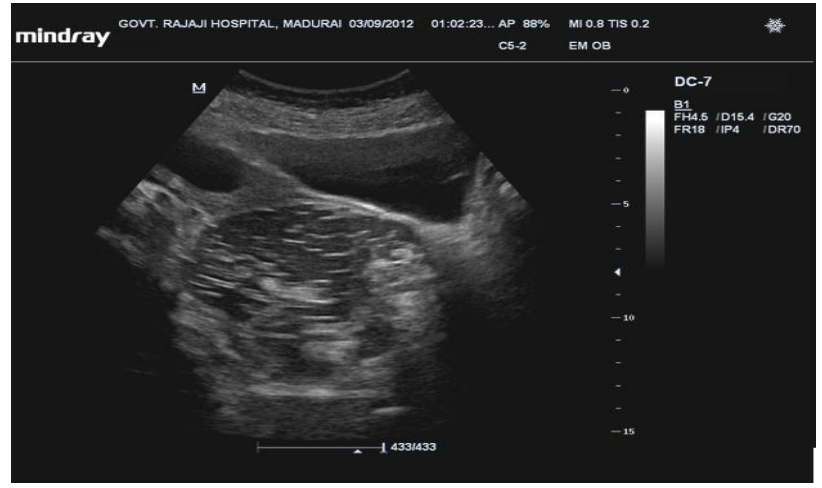

Figure 2: Smooth wall, diffuse echogenicity (Score 1).

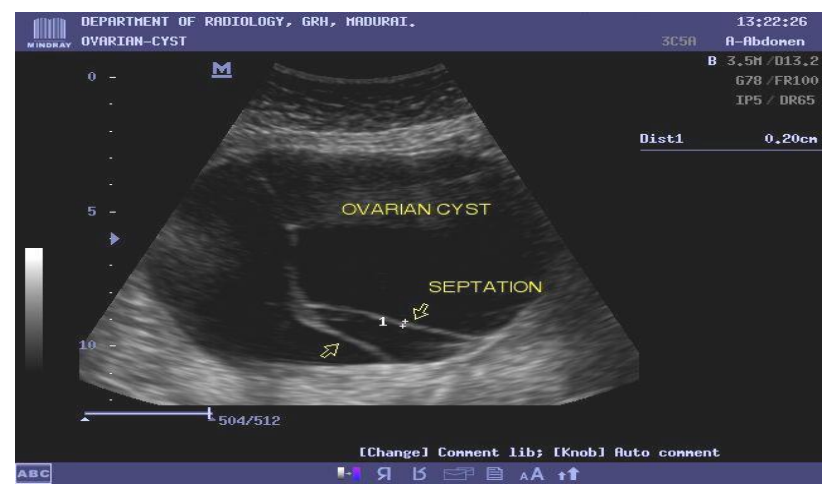

Figure 3: Wall thickening, $<3 \mathrm{~mm}$ fine Septa (Score 2).



Figure 4: Papillary projections, Septa $>3 \mathrm{~mm}$ (Score 3).

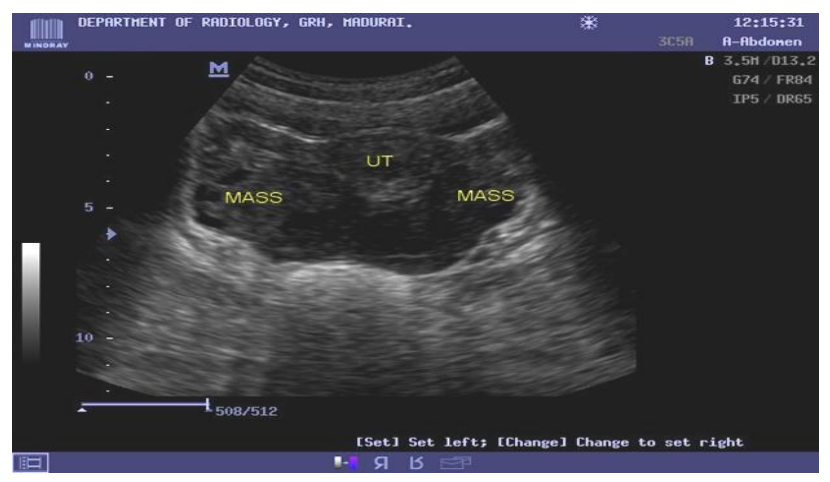

Figure 5: Complex, predominantly solid (Score 4). 


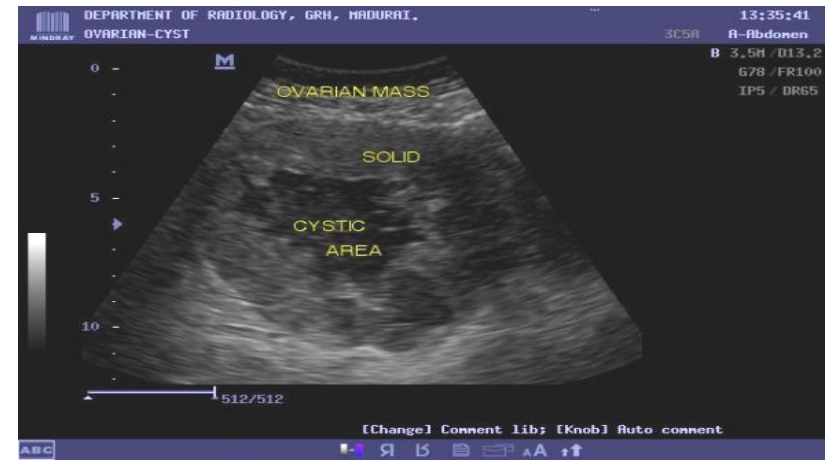

Figure 6: Complex, solid and cystic areas with extratumoral fluid (Score 5).



Figure 7: Extratumoral fluid (Score 5).

Table 1: Sonographic morphology index for ovarian tumors.

\begin{tabular}{|c|c|c|c|c|c|c|}
\hline & \multicolumn{6}{|l|}{ Category } \\
\hline & 0 & 1 & 2 & 3 & 4 & 5 \\
\hline $\begin{array}{l}\text { Volume* } \\
\left(\mathrm{cm}^{3}\right)\end{array}$ & $<10$ & $10-50$ & $>50-100$ & $>100-200$ & $>200-500$ & $>500$ \\
\hline structure & $\begin{array}{l}\text { Smooth wall, } \\
\text { sonolucent }\end{array}$ & $\begin{array}{l}\text { Smooth } \\
\text { wall, diffuse } \\
\text { echogenicity }\end{array}$ & $\begin{array}{l}\text { Wall } \\
\text { thickening, <3- } \\
\text { mm fine septa }\end{array}$ & $\begin{array}{l}\text { Papillary } \\
\text { projection } \\
>3 \mathrm{~mm}\end{array}$ & $\begin{array}{l}\text { Complex, } \\
\text { predominantly } \\
\text { solid }\end{array}$ & $\begin{array}{l}\text { Complex, solid } \\
\text { and cystic areas } \\
\text { with extratumoral } \\
\text { fluid }\end{array}$ \\
\hline
\end{tabular}

*Calculated using prolate ellipsoid formula ( $\mathrm{L}$ x W x H x 0.523)

Two different descriptive categories were evaluated:

- Volume of tumor and

- Morphologic features.

A point scale from 0-5 was assigned for each of the component. A total score ranging from 0 to 10 for each tumor (Table 1). Following morphology indexing, each tumor was surgically removed and sent for histopathological examination.

\section{Statistical analysis}

The results were collected in a standardized Performa. Statistical evaluation of the data was performed using univariate and multivariate analyses. Proportions were compared using the $\mathrm{x}^{2}$ statistic from the corresponding contingency tables. Means were compared using the twotailed t statistic. Logistic regression was used for the multivariate analyses. Statistical significance was determined at the 0.05. The statistical software SPSS V.19 was used for statistical analysis.

\section{RESULTS}

The clinical parameters of the patients evaluated are as follows: mean age 40.5 years (range, $13-85$ years); mean height $154 \mathrm{cms}$. (Range, 145-165cms.); and mean weight $56 \mathrm{~kg}$ (range, $45 \mathrm{~kg}-90 \mathrm{~kg}$ ). Sixty patients were 40 years of age or older and seventy-six were under the age of 40 years.

Table 2 illustrates the score for tumors based on the tumor volume. Most benign tuomrs have a score of $<3$ and most of the malignant tumors are more have a score $>4$

Table 3 illustrates the score for tumors based on the tumor structures. Most benign tumors have a structural score $<2$ and most malignant tumors have a structural score $>3$.

Table 4 illustrates the total of volume and structural score, consolidated as the morphological score. Most of the benign tumors have a score of $<5$ and score of $>5$ suggests malignancy. The modified MI was easy to interpret, and each structural category was distinct. As a result, the interobserver variation in morphology scoring was minimal. In a blinded comparison of the MI score by two of the authors (S.D. and R.S.), the identical score was recorded in 134 of 136 cases $(98.5 \%)$. In the remaining 2 cases, the morphology score varied only by +1 . Risk of malignancy in an ovarian tumor was related directly to structural complexity ( $\mathrm{P}<0.001)$, tumor volume (P $<0.001)$, and total MI score $(\mathrm{P}<0.001)$ (Table 2, 3). 
Table 2: Distribution of cases according to USG volume Score.

\begin{tabular}{|c|c|c|c|c|c|c|c|c|}
\hline \multirow{3}{*}{ USG Volume Score } & \multicolumn{6}{|c|}{ Number of cases } & \multirow{2}{*}{\multicolumn{2}{|c|}{ Total cases }} \\
\hline & \multicolumn{2}{|c|}{ Benign } & \multicolumn{2}{|c|}{ Borderline } & \multicolumn{2}{|c|}{ Malignant } & & \\
\hline & No. & $\%$ & No. & $\%$ & No. & $\%$ & No. & $\%$ \\
\hline 0 & 1 & 100 & - & - & - & - & 1 & 0.7 \\
\hline 1 & 8 & 100 & - & - & - & - & 8 & 5.9 \\
\hline 2 & 8 & 66.7 & 2 & 16.7 & 2 & 16.7 & 12 & 8.8 \\
\hline 3 & 23 & 85.2 & - & - & 4 & 14.8 & 27 & 19.9 \\
\hline 4 & 27 & 87.1 & - & - & 4 & 12.9 & 31 & 22.8 \\
\hline 5 & 25 & 43.9 & 1 & 1.8 & 31 & 54.4 & 57 & 41.9 \\
\hline Total & 92 & 100 & 3 & 100 & 41 & 100 & 136 & 100 \\
\hline Range & $1-5$ & & $2-5$ & & $0-5$ & & $0-5$ & \\
\hline Mean & 3.54 & & 3.0 & & 4.45 & & 3.84 & \\
\hline S.D. & 1.23 & & 1.73 & & 1.11 & & 1.27 & \\
\hline 'p' & $<0.0$ & & & & & & & \\
\hline
\end{tabular}

Table 3: Distribution of cases according to structural score.

\begin{tabular}{|c|c|c|c|c|c|c|c|c|}
\hline \multirow{3}{*}{ Structural Score } & \multicolumn{6}{|c|}{ Number of cases } & \multirow{2}{*}{\multicolumn{2}{|c|}{ Total cases }} \\
\hline & \multicolumn{2}{|c|}{ Benign } & \multicolumn{2}{|c|}{ Borderline } & \multicolumn{2}{|c|}{ Malignant } & & \\
\hline & No. & $\%$ & No. & $\%$ & No. & $\%$ & No. & $\%$ \\
\hline 0 & 56 & 96.6 & - & - & 2 & 3.4 & 60 & 44.1 \\
\hline 1 & 19 & 90.5 & - & - & 2 & 9.5 & 21 & 15.4 \\
\hline 2 & 6 & 75 & - & - & 2 & 25 & 8 & 5.9 \\
\hline 3 & 5 & 62.5 & - & - & 3 & 37.5 & 8 & 5.9 \\
\hline 4 & 2 & 13.3 & 1 & 6.7 & 12 & 80 & 15 & 11 \\
\hline 5 & 2 & 8.3 & 2 & 8.3 & 20 & 83.3 & 24 & 17.6 \\
\hline Total & 92 & 100 & 3 & 100 & 41 & 100 & 136 & 100 \\
\hline Range & $0-5$ & & $4-5$ & & $0-5$ & & $0-5$ & \\
\hline Mean & 0.7 & & 4.67 & & 3.88 & & 1.77 & \\
\hline S.D. & 1.18 & & 0.58 & & 1.53 & & 2.0 & \\
\hline 'p' & $<0.0$ & & & & & & & \\
\hline
\end{tabular}

Table 4: Distribution of cases according to total morphological score.

\begin{tabular}{|c|c|c|c|c|}
\hline Morphological index score & $\mathbf{N}$ & Benign & Borderline & Malignant \\
\hline 0 & 1 & $1(100 \%)$ & & \\
\hline 1 & 6 & $6(100 \%)$ & & \\
\hline 2 & 7 & $7(100 \%)$ & & \\
\hline 3 & 19 & $19(100 \%)$ & & \\
\hline 4 & 21 & $19(90.5 \%)$ & & $2(9.5 \%)$ \\
\hline 5 & 21 & $20(95.2 \%)$ & & $1(4.8 \%)$ \\
\hline 6 & 15 & $12(80 \%)$ & & $3(20 \%)$ \\
\hline 7 & 7 & $3(42.9 \%)$ & $2(28.6 \%)$ & $2(28.6 \%)$ \\
\hline 8 & 8 & $1(12.5 \%)$ & & $7(87.5 \%)$ \\
\hline 9 & 15 & $3(20 \%)$ & $1(6.7 \%)$ & $11(73.3 \%)$ \\
\hline 10 & 16 & $1(6.3 \%)$ & & $15(93.8 \%)$ \\
\hline Total & 136 & 92 & 3 & 41 \\
\hline
\end{tabular}

There were only two malignancies in 54 ovarian tumors $(0.3 \%)$ with a MI <5. In contrast, there were 39 malignancies in 82 ovarian tumors $(47.5 \%)$ with a $\mathrm{MI}>5$ ( $\mathrm{P}<0.01)$. Risk of malignancy varied from $3.7 \%$ in ovarian tumors having a MI $<5$ to $87.2 \%$ in tumors with a MI >7 (Table 4).
A MI value of $>5$ as indicative of malignancy was associated with the following statistical parameters: sensitivity 0.955 , specificity 0.565 , positive predictive value (PPV) 0.512, negative predictive value (NPV) 0.963 , and accuracy 0.691 (Table 5). 
Table 5: Statistical parameters associated with a morphology index value $\geq 5$ predictive of ovarian malignancy.

\begin{tabular}{|llll|}
\hline Sensitivity & TP/TP+FN & $42 / 42+3$ & 95.5 \\
\hline $\begin{array}{l}\text { Specificity } \\
\begin{array}{l}\text { Positive predictive } \\
\text { value }\end{array}\end{array}$ & TN/TN+FP & $51 / 51+40$ & 56.5 \\
\hline $\begin{array}{l}\text { Negative } \\
\text { predictive value }\end{array}$ & TN/TN+FN & $42 / 42+40$ & 51.2 \\
Accuracy & $\begin{array}{l}\text { TP+TN/ } \\
\text { TP+TN+FN }\end{array}$ & $42+51 / 42$ & 96.3 \\
& $+F P$ & $+51+3+40$ & 69.1 \\
\hline
\end{tabular}

\section{DISCUSSION}

With the demand for Evidence Based Medicine it has become a challenging task to develop a morphological index to predict the malignancy of ovarian mass without any surgical intervention. ${ }^{7}$ An ideal scoring system must be accurate, easy to interpret, time saving, less interobserver bias and cost effective. The use of such a scoring system must help in triaging the women with malignancy to oncologists and avoid unwanted surgical intervention in women with benign tumors.

Several investigators have put forth many scoring system to compare the morphological features of the tumors. ${ }^{6,8,9}$ The present Morphological Indexing is a modification of the scoring system proposed by DePriest and colleagues. ${ }^{6}$ By incorporating findings of intratumoral septa, diffuse echogenicity and extratumoral free fluid into structural evaluation, the sensitivity, specificity, PPV, and NPV of the modified MI all increased. In the present study sensitivity, specificity, PPV and NPV was found to be $95.5 \%, 56.5 \%, 51.2 \%, 96.3 \%$ respectively. Similar statistical significance was observed by Lerner et al DePriest et al and Ferrazzi et al. ${ }^{6,10,11}$

According to the present study the benign tumors have a mean volume score of 3.58 which is statistically significant (Table 2). This mean deviation to the higher value is mainly contributed by the benign mucinous cystadenoma which were larger in size with a volume of $>500$. The malignant ovarian tumors have a mean volume score of 4.45 which is statistically significant.

In the present study, benign tumours had a mean structural score of 0.7 and malignant tumors had a mean structural score of 3.88 (Table 3 ). Of the benign tumors most of them had a smooth wall with either sonolucent or diffuse echogenicity accounting for a score of 0 or 1 . Of the malignant tumors most of them should a complex, solid and cystic areas with extramural fluid accounting for a score of 5 .

In the present study, using a MI value $<5$ as indicative of benign disease was associated with only two false positive cases in 54 ovarian tumors. Both these patients had a small solid tumor which on histopathology was confirmed as serous cystadenocarcinoma. Out of the 54 ovarian tumors 46 cases were cystic ovarian tumors and none of them developed malignancy. These findings correlated with studies done by Bailey et al and Ueland et al and suggest that cystic ovarian tumors $<5 \mathrm{~cm}$ can be followed up without surgical intervention but any solid or complex ovarian tumors must be surgically removed for histopathological confirmation of the nature of the tumor irrespective of their size. ${ }^{12,13}$ Present study further supports these conclusion by the fact that out of the 55complex malignant ovarian tumors 41 (74.5\%) were malignant ovarian tumors which is significant.

In the present study, the morphological index score of $>5$ as a predictor of malignancy has statistical parameters as follows:

- Sensitivity-95.5\%,

- Specificity-56.5\%,

- Positive predictive value-51.2\%,

- Negative predictive value-96.3\%, and

- Accuracy-69.1\%.

These parameters were much less than that observed by Ueland et al reported a sensitivity of $98.1 \%$, specificity of $80.7 \%$, positive predictive value of $40.9 \%$, negative predictive value of $99.7 \%$, and accuracy of $82.8 \%$.

Table 6: Comparisons of sensitivity and specificity with other Studies.

\begin{tabular}{|llll|}
\hline Source & Year & Sensitivity & Specificity \\
\hline Granberg et al & 1991 & 0.82 & 0.92 \\
\hline Sassone et al & 1991 & 1.0 & 0.83 \\
\hline Lerner et al & 1994 & 0.97 & 0.77 \\
\hline DePriest et al & 1994 & 0.89 & 0.70 \\
\hline Yamashita et al & 1997 & 0.85 & 0.78 \\
\hline Ferrazzi et al & 1997 & 0.75 & 0.67 \\
\hline Present study & 2012 & 0.95 & 0.56 \\
\hline
\end{tabular}

The sensitivity at which the diagnosis of malignancy is made should be almost perfect in order to prevent patients being operated upon under suboptimal conditions and avoid spillage during surgery. ${ }^{14}$ Although spillage during surgery has not proven to affect survival, these cells are capable of implantation on peritoneal surfaces theoretically. ${ }^{15}$ In the absence of clear evidence that spillage does not affect survival, it is better that spillage need to be avoided in patients with malignancy. ${ }^{16}$ Table 6 illustrates the sensitivity and specificity of various studies. ${ }^{8-11,15,16}$ These individual studies were subjected to observer bias. Mol et al did an external validation of these sonological indices and revealed a lower accuracy with a high sensitivity ranging from $77-93 \%$ can be achieved only at the expense of a wide range in specificity ranging from $21-89 \% .{ }^{14}$ In the present study we have documented a high sensitivity at the expense of the specificity of the test. Hence, standardization of 
ultrasound is an essential tool in differentiating benign from malignant ovarian tumors.

\section{CONCLUSION}

The findings of the present investigation conclude that morphologic indexing is a reliable method to predict risk of malignancy in ovarian tumors. It is simple and easy to perform although subjected to minimal interobserver variation. Morphologic indexing helps to standardise the ultrasound reading without adding costs. The use of morphology indexing can identify ovarian tumors at high risk for malignancy and allow appropriate triage of these patients to a gynaecologic oncologist if needed and also effectively decreases the need for unnecessary radical surgery in benign ovarian tumor.

\section{ACKNOWLEDGMENTS}

Authors would like to thank all the patients for their support during the study.

\section{Funding: No funding sources}

Conflict of interest: None declared

Ethical approval: The study was approved by the Institutional Ethics Committee

\section{REFERENCES}

1. Cancer Incidence in Five Continents - WHO - OMS [Internet]. [cited 2017 May 17]. Available at http://apps.who.int/bookorders/anglais/detart1.jsp?co dlan $=1 \&$ codcol $=73 \&$ codcch $=143$

2. Murthy NS, Shalini S, Suman G, Pruthvish S, Mathew A. Changing trends in incidence of ovarian cancer - the Indian scenario. Asian Pac J Cancer Prev. 2009; 10(6):1025-30.

3. 3. Takiar R, Nadayil D, Nandakumar A. Projections of number of cancer cases in India (20102020) by cancer groups. Asian Pac J Cancer Prev. 2010;11(4):1045-9.

4. van Nagell JR, DePriest PD, Gallion HH, Pavlik EJ. Ovarian cancer screening. Cancer. 1993;71(4 Suppl):1523-8.

5. Yelikar KA, Deshpande SS, Nanaware SS, Pagare SB. Evaluation of the validity of risk malignancy index in clinically diagnosed ovarian masses and to compare it with the validity of individual constituent parameter of risk malignancy index. Int J Reprod Contracept Obstet Gynecol. 2016;5(2):460-4.

6. DePriest PD, Shenson D, Fried A, Hunter JE, Andrews SJ, Gallion HH, et al. A morphology index based on sonographic findings in ovarian cancer. Gynecol Oncol. 1993;51(1):7-11.

7. Partridge EE, Barnes MN. Epithelial ovarian cancer: prevention, diagnosis, and treatment. CA Cancer $\mathrm{J}$ Clin. 1999;49(5):297-320.

8. Sassone AM, Timor-Tritsch IE, Artner A, Westhoff C, Warren WB. Transvaginal sonographic characterization of ovarian disease: evaluation of a new scoring system to predict ovarian malignancy. Obstet Gynecol. 1991;78(1):70-6.

9. DePriest PD, Varner E, Powell J, Fried A, Puls L, Higgins R, et al. The efficacy of a sonographic morphology index in identifying ovarian cancer: a multi-institutional investigation. Gynecol Oncol. 1994;55(2):174-8.

10. Lerner JP, Timor-Tritsch IE, Federman A, Abramovich G. Transvaginal ultrasonographic characterization of ovarian masses with an improved, weighted scoring system. Am J Obstet Gynecol. 1994;170(1 Pt 1):81-5.

11. Ferrazzi E, Zanetta G, Dordoni D, Berlanda N, Mezzopane R, Lissoni AA et al. Transvaginal ultrasonographic characterization of ovarian masses: comparison of five scoring systems in a multicenter study. Ultrasound Obstet Gynecol. 1997;10(3):192-7.

12. Bailey CL, Ueland FR, Land GL, DePriest PD, Gallion HH, Kryscio RJ et al. The malignant potential of small cystic ovarian tumors in women over 50 years of age. Gynecol Oncol. 1998;69(1):37.

13. Ueland FR, DePriest PD, Pavlik EJ, Kryscio RJ, van Nagell JR. Preoperative differentiation of malignant from benign ovarian tumors: the efficacy of morphology indexing and Doppler flow sonography. Gynecol Oncol. 2003;91(1):46-50.

14. Trimbos JB, Hacker NF. The case against aspirating ovarian cysts. Cancer. 1993;72(3):828-31.

15. Granberg S, Norström A, Wikland M. Tumors in the lower pelvis as imaged by vaginal sonography. Gynecol Oncol. 1990;37(2):224-9.

16. Yamashita Y, Hatanaka Y, Torashima M, Takahashi M, Miyazaki K, Okamura H. Characterization of sonographically indeterminate ovarian tumors with MR imaging. A logistic regression analysis. Acta Radiol. 1997;38(4 Pt 1):572-7.

Cite this article as: Aishwarya J, Sasikala R,

Dilshath S. Efficacy of morphological indexing of ovarian tumor: preoperative determination of risk of malignancy. Int J Reprod Contracept Obstet Gynecol 2017;6:3458-63. 